\title{
Aripiprazole for the maintenance treatment of bipolar disorder: a review of available evidence
}

This article was published in the following Dove Press journal:

Neuropsychiatric Disease and Treatment

25 May 20II

Number of times this article has been viewed

\author{
Roger S Mclntyre ${ }^{1,2,3,4}$ \\ jinju Yoon ${ }^{3}$ \\ Jeanette $M$ Jerrell ${ }^{5}$ \\ Samantha S Liauw ${ }^{3}$ \\ 'Department of Psychiatry, University \\ of Toronto, Toronto, ON, Canada; \\ 2Department of Pharmacology, \\ University of Toronto, Toronto, \\ ON, Canada; ${ }^{3}$ Mood Disorders \\ Psychopharmacology Unit, University \\ Health Network, Toronto, ON, \\ Canada; ${ }^{4}$ Institute of Medical Science, \\ University of Toronto, Toronto, \\ ON, Canada; ${ }^{5}$ Department of \\ Neuropsychiatry and Behavioral \\ Science, University of South Carolina \\ School of Medicine, Columbia, SC, USA
}

Correspondence: Roger S Mclntyre Associate Professor of Psychiatry and Pharmacology, University of Toronto, Mood Disorders Psychopharmacology Unit, University Health Network, 399 Bathurst Street, Toronto, ON, Canada M5T 2S8

$\mathrm{Tel}+\mathrm{I} 4166035279$

Fax + I 4166035368

Email roger.mcintyre@uhn.on.ca

\begin{abstract}
We aimed to review and synthesize results reporting on the maintenance efficacy of Aripiprazole in adults with bipolar I disorder. Aripiprazole is FDA approved for the acute and maintenance treatment of bipolar I disorder. Aripiprazole's efficacy during the long-term treatment of bipolar disorder is supported by extension of acute phase studies and long-term (ie, 100week) double-blind placebo controlled recurrence prevention registration trials. Aripiprazole is not established as efficacious in the acute or maintenance treatment of bipolar depression. Moreover, aripiprazole's efficacy during the acute or maintenance phase of bipolar II disorder has not been sufficiently studied. Aripiprazole has a relatively lower hazard for metabolic disruption and change in body composition when compared to other atypical agents (eg, olanzapine, quetiapine). Moreover, aripiprazole has minimal propensity for sedation, somnolence and prolactin elevation. Aripiprazole is associated with extrapyramidal side effects, notably akathisia, which in most cases is not severe or treatment limiting. Future research vistas are to explore aripiprazole's efficacy in bipolar subgroups; recurrence prevention of bipolar depression; and in combination with other mood stabilizing agents.
\end{abstract}

Keywords: aripiprazole, bipolar disorder, maintenance, pharmacology

\section{Introduction}

During the past decade, the US FDA has approved several agents for the maintenance treatment of bipolar disorder (BD). Aripiprazole is approved as monotherapy and adjunctive treatment for the acute and maintenance treatment of adults with bipolar I disorder and for the treatment of pediatric mania. Several reviews have been published by ourselves and other groups pertinent to aripiprazole's efficacy in bipolar mania and depression and will not be reviewed herein. ${ }^{1}$ Increasingly, the therapeutic emphasis in $\mathrm{BD}$ has been on the maintenance phase, largely due to increased recognition of the illness burden attributable to BD. Moreover, the long-term hazards of many psychotropic agents on body composition and metabolic parameters have differentiated aripiprazole as an alternative with a lower propensity toward adverse metabolic outcomes.

\section{Methods}

We conducted a PubMed search of all English-language articles published between January 1995 and January 2011. The key search term was aripiprazole combined with: randomized controlled trials, pharmacology, pharmacokinetics, pharmacodynamics, depression, mania, maintenance and $\mathrm{BD}$. The search was augmented with a manual review of relevant article reference lists. We delimited our review to pivotal maintenance randomized controlled registration trials in BD. 


\section{Aripiprazole: pharmacokinetics/ pharmacodynamics \\ Pharmacokinetics}

Aripiprazole is available in oral compressed tablet, oral disintegrating tablet, non-refrigerated oral solution, and intramuscular formulations. ${ }^{2}$ Aripiprazole tablets are available in 2-, 5-, 10-, 15-, 20- and 30-mg strengths. The effective dose range for patients with bipolar I disorder is between 15 and $30 \mathrm{mg}$ /day. Orally disintegrating tablets are available in $10 \mathrm{mg}$ and $15 \mathrm{mg}$ strengths. In addition, aripiprazole is available in a $1 \mathrm{mg} / \mathrm{mL}$ non-refrigerated oral solution. Parenteral aripiprazole is intended for intramuscular use only and is available in several $7.5 \mathrm{mg} / \mathrm{mL}$ doses (ie, $5.25 \mathrm{mg} / 0.7 \mathrm{~mL}$, $9.75 \mathrm{mg} / 1.3 \mathrm{~mL}$, and $15 \mathrm{mg} / 2 \mathrm{~mL}$ ) of clear, colorless, sterile, aqueous solution. ${ }^{3}$ The oral formulation of aripiprazole is indicated for the acute and maintenance treatment of schizophrenia and $\mathrm{BD}$, whereas the parenteral formulation is indicated for agitation associated with schizophrenia or bipolar mania.

The compressed tablets are extensively absorbed through the gastrointestinal tract with a bioavailability of $87 \%$. The time to peak plasma concentration $\left(\mathrm{T}_{\max }\right)$ is $3-5$ hours for aripiprazole; food intake does not significantly affect peak plasma concentration $\left(\mathrm{C}_{\max }\right)$ but may delay $\mathrm{T}_{\max }{ }^{4}$ Aripiprazole exhibits linear pharmacokinetics between the dosing ranges of 5-30 mg/day. At equivalent doses (ie, $30 \mathrm{mg}$ /day), the plasma concentration of aripiprazole oral solution was higher than that of the compressed tablet, ie, the solution-to-tablet ratio of geometric $\mathrm{C}_{\max }$ and area under concentration-time curve (AUC) values were $122 \%$ and $114 \%$. Aripiprazole oral disintegrating tablets are bioequivalent to the compressed tablets. The time to peak plasma concentration with aripiprazole injection is 1-3 hours and has an absolute bioavailability of $100 \%$. The geometric mean $\mathrm{C}_{\max }$ achieved after an intramuscular (IM) dose was approximately $19 \%$ higher than the $\mathrm{C}_{\max }$ of the oral tablet; the aripiprazole AUC in the first 2 hours after the initial IM injection is $90 \%$ greater than the AUC after a similar tablet dose. Over 24 hours of dosing, the systemic exposure is similar between aripiprazole injection and oral tablet administration. ${ }^{3}$

The half-life of aripiprazole is longer than other atypical agents, ie, 48-75 hours for aripiprazole and 94 hours for the active principal metabolite, dehydroaripiprazole. Steady state with aripiprazole is achieved within 14 days of administration. ${ }^{4}$ The volume of distribution of aripiprazole is $404 \mathrm{~L}$ $(4.9 \mathrm{~L} / \mathrm{kg})$ and it is extensively bound to plasma proteins (99\%). Aripiprazole is metabolized mainly in the liver via the cytochrome P450 (CYP) enzymes 3A4 and 2D6, primarily via dehydrogenation, hydroxylation and $\mathrm{N}$-dealkylation. ${ }^{4}$ Approximately $40 \%$ of aripiprazole AUC in plasma is comprised of dehydroaripiprazole. Slow metabolizers at CYP3A4 or CYP2D6 exhibit an increase in $\mathrm{C}_{\max }$ ie, an $80 \%$ increase in aripiprazole exposure and $30 \%$ decrease in active metabolite exposure and half-life (ie, 146 hours versus $48-75$ hours) and will require adjustment of dosing. ${ }^{4}$ Excretion of aripiprazole occurs via the kidney and liver with $25 \%$ and $55 \%$ of the dose recovered in the urine and feces respectively.,4

Aripiprazole does not induce or inhibit CYP enzymes $3 \mathrm{~A} 4$ and 2D6. Aripiprazole does not alter the pharmacokinetics of divalproex sodium or lithium and vice versa. Although renal and hepatic impairment results in an increase in $\mathrm{C}_{\max }$, dosage adjustment is not required. Although $\mathrm{C}_{\max }$ and $\mathrm{AUC}$ is $30 \%$ and $40 \%$ higher respectively in women than men, no dosing adjustment is necessary. ${ }^{2,4}$

\section{Pharmacodynamics}

Aripiprazole is a highly lipid soluble quinolone-derived novel psychotropic agent. ${ }^{5,6}$ Aripiprazole's receptor profile has been well characterized pre-clinically in vitro and in vivo. ${ }^{7}$ Aripiprazole exhibits high receptor affinity for $\mathrm{D}_{2}$ and $\mathrm{D}_{3}$ receptors with moderate affinity for $\mathrm{D}_{4}$ receptors. Aripiprazole acts as a partial agonist at the pre-synaptic dopamine autoreceptors and post-synaptic $\mathrm{D}_{2}$ receptors (where it may have a higher intrinsic activity). ${ }^{8,9}$ This in vitro profile provides for functional antagonism in hyperdopaminergic states and functional agonism in hypodopaminergic states. ${ }^{10}$ Dehydroaripiprazole, has similar pharmacodynamic effects at the $\mathrm{D}_{2}$ receptors. $^{7}$

Aripiprazole exhibits high affinity for $5-\mathrm{HT}_{1 \mathrm{~A}}$ and $5-\mathrm{HT}_{2 \mathrm{~A}}$ receptors, resulting in partial agonism and antagonism respectively. The partial agonism at the $5-\mathrm{HT}_{1 \mathrm{~A}}$ receptor is similar to the anxiolytic azapirones. ${ }^{11}$ Aripiprazole is an inverse agonist at 5- $\mathrm{HT}_{2 \mathrm{~B}}$ receptors and a partial agonist at $5-\mathrm{HT}_{2 \mathrm{C}}, 5-\mathrm{HT}_{7}, \mathrm{D}_{3}$ and $\mathrm{D}_{4}$ receptors. Aripiprazole displays low affinity for H1-histaminergic, muscarinic, cholinergic, and adrenergic receptors. This profile is predictive of low propensity to extrapyramidal symptoms (EPS), weight-gain, metabolic disruption, hyperprolactinemia and sedation. ${ }^{12}$

\section{Aripiprazole: maintenance treatment in bipolar disorder}

A single randomized, double-blind parallel group placebocontrolled study reported on the safety and efficacy of aripiprazole in preventing relapse of a mood episode in recently manic, or mixed episode patients with bipolar I disorder stabilized with aripiprazole. ${ }^{13-15}$ This multiphase study 
began with an open-label stabilization phase followed by a double-blind phase that extended to 100 weeks.

During the stabilization phase, patients received openlabel treatment with aripiprazole 15 or $30 \mathrm{mg} /$ day for 6-18 weeks. Patients meeting stabilization criteria [ie, Young Mania Rating Scale (YMRS) total score $\leq 10$ and Montgomery Asberg Depression Rating Scale (MADRS) total score of $\leq 13$ during 4 consecutive visits over a minimum of 6 weeks] were eligible for the double-blind phase in which they were randomized to the aripiprazole dose received at the end of the stabilization phase or placebo.

The primary efficacy parameter was time to relapse for a mood episode (ie, manic, depressive or mixed) during the double-blind phase. Relapse was defined by discontinuation due to inefficacy (ie, hospital admission due to mood episode), and/or addition to or increase in psychotropic medication other than study drug for manic and/or depressive symptoms. Secondary efficacy parameters were time to manic and depressive relapse and change from randomization to endpoint on continuous efficacy metrics [ie, YMRS, MADRS, Clinical Global Impression for use in bipolar illness (CGI-BP), and Positive and Negative Syndrome Scale (PANSS) total score as well as cognitive and hostility subscales].

Five hundred and sixty-seven patients entered the stabilization phase, which included 333 who had participated in earlier studies of aripiprazole. Of the total, 206 completed the stabilization phase, 161 entered the double-blind phase and 67 completed the double-blind phase. At 26 weeks, the mean aripiprazole dose was $24.3 \mathrm{mg} /$ day. Most patients (71\%) in both groups required at least one concomitant medication. Time to relapse was significantly longer for aripiprazoletreated patients than for placebo-treated patients $(P=0.02)$. The mean change from baseline to end-point in YMRS total score, PANSS cognitive subscale score and CGI-BP severity was superior in the aripiprazole-treated group compared to placebo.

More patients receiving placebo discontinued the study prematurely due to treatment emergent adverse events (TEAE) (19\%) versus aripiprazole $(10 \%)$. The five most commonly reported TEAEs $(\geq 5 \%)$ in the aripiprazole-treated group were anxiety $(17 \%)$, insomnia $(16 \%)$, depression $(12 \%)$, nervousness $(10 \%)$, and tremor $(9 \%)$. For placebo, the most commonly reported TEAEs were insomnia (19\%), headache $(17 \%)$, anxiety (15\%), depression (15\%), and manic reaction $(13 \%)$. The rates of EPS were higher in the aripiprazole group; tremor was the most frequently reported EPS. A higher percentage of patients receiving aripiprazole had significant elevation of Simpson Angus Scale (SAS) and Barnes Akathisia Rating Scale (BARS) total scores.

Mean weight change from randomization to endpoint was $-1.7+/-0.8 \mathrm{~kg}$ and $+0.5+/-0.8 \mathrm{~kg}$ for placebo and aripiprazole, respectively. At the end of 26 weeks of treatment, significant weight-gain was observed in $13 \%$ of the aripiprazole treated patients and none of the placebo-treated patients. Aripiprazole-treated patients exhibited a non-significant decrease in mean serum prolactin concentration from randomization to end-point. No significant changes were noted in vital signs, corrected QT interval (QTc), fasting glucose, high-density lipoprotein (HDL), or low-density lipoprotein (LDL) concentration.

A 74-week extension study, which included the cohort from the 26-week study, was subsequently published. The inclusion and exclusion criteria of the extension study as weel as its definition of relapse were identical to the 26-week double-blind phase. In total, of the 67 patients who completed the initial 26-week double-blind phase, 66 entered the 74-week extension phase. During the 74-week extension, there were more discontinuations due to lack of efficacy from the placebo group (26\%) than the aripiprazole group (13\%). The mean aripiprazole dose during the combined 26-week and 74-week double-blind phases was $24.1 \mathrm{mg} /$ day.

Time to relapse into any mood episode during doubleblind treatment was significantly longer for patients who received aripiprazole than placebo. Time to manic relapse was significantly longer for aripiprazole treated than placebo treated patients. There were no differences in time to depressive relapses between groups. The mean change in YMRS total score from baseline of the double-blind phase to week 100 was significantly greater in the placebo versus the aripiprazole group. There were no differences between groups from baseline to week 100 in the total MADRS score. Improvements on the PANSS cognitive subscale score and PANSS hostility subscale were significantly greater for aripiprazole. The mean change from baseline to week 100 in the CGI-BP severity illness score was greater in aripiprazole treated subjects.

Adverse events related to EPS occurred more frequently with aripiprazole compared to placebo $(22 \%$ versus $15 \%)$. The most common EPS were tremor (9\% versus $1 \%)$, akathisia ( $8 \%$ versus $1 \%$ ), and hypertonia ( $4 \%$ versus $2 \%$ ). Mean change from baseline of the double-blind phase to week 100 on the SAS, AIMS, and BARS were not significantly different between groups. The mean weight change in patients treated with placebo was $-1.9 \pm 0.8 \mathrm{~kg}$ and $0.4 \pm 0.8 \mathrm{~kg}$ with aripiprazole. 
A separate randomized double-blind active agent and placebo-controlled study compared long-term efficacy and tolerability of aripiprazole with lithium monotherapy in the acute and maintenance treatment of bipolar I disorder. ${ }^{17}$ Patients with acute bipolar mania or mixed states who required hospitalization were randomized to receive aripiprazole 15-30 mg/day, lithium 900-1500 mg or placebo for 3 weeks. At the completion of 3 weeks, those who had been randomized to placebo during the 3 week phase were blindly switched to aripiprazole whereas aripiprazole- and lithium-treated patients continued with their assigned treatment.

All patients continued double-blind treatment to week 12 at which time they could enter a 40 -week double-blind extension phase. At week $12,27 \%, 34 \%$, and $29 \%$ of subjects receiving aripiprazole, lithium or placebo respectively completed the treatment. Improvement in mean YMRS total score was significantly greater with aripiprazole compared with placebo beginning at day 2 and extending to week 3 . Lithium was associated with significant improvement compared to placebo at week 3 . The most commonly encountered TEAEs with aripiprazole and lithium were headache ( $23 \%$ and $22 \%$ respectively), nausea (23\% and $24 \%$ ), akathisia (15\% and $5 \%$ ), sedation (13\% and $7 \%$ ), constipation ( $10 \%$ and $13 \%)$, and tremor $(8 \%$ and $12 \%)$. There were no differences between aripiprazole and lithium treated subjects in total weight gain.

A separate 46-week open-label study evaluated the maintenance efficacy of aripiprazole in combination with lithium or valproate in the treatment of adults with BD. ${ }^{18}$ This 46-week study represented an extension of a previous 6-week study evaluating the combination of aripiprazole with lithium or divalproex..$^{19}$ Patients with bipolar mania or mixed states with a partial non-response to lithium/valproate monotherapy (ie, YMRS total score $\geq 16$ after at least 2 weeks of lithium/ valproate monotherapy) were eligible for enrolment to receive either aripiprazole 15 or $30 \mathrm{mg}$ or placebo for 6 weeks.

Efficacy was assessed by the mean change in the YMRS and MADRS total scores from the end of the 6-week double-blind phase to week 46 . Of the 384 patients who were randomized to the 6-week double-blind treatment phase, 310 completed and 283 were eligible to enter the open-label extension phase. Of the 283 patients, 146 (51.6\%) patients completed the 46-week open-label extension phase. The mean daily dose of aripiprazole during the extension phase was $17.9 \mathrm{mg} /$ day.

Continued improvement in the YMRS total score throughout the open-label phase was noted from baseline to week 52 . Overall reduction in MADRS score through the extension phase was minimal; as subjects were manic at study entry, the trial design is not sufficient to evaluate acute or prophylactic antidepressant effects.
Extrapyramidal side effects were reported in 24 (22.6\%) of patients in the aripiprazole plus lithium group and 38 patients $(21.8 \%)$ in the aripiprazole plus valproic acid group. The most commonly reported EPS were tremor and akathisia. Minimal changes were observed on the SAS, AIMS or BARS. Mean change in weight from the end of the 6-week double-blind phase to week 46 of the open label phase was $2.1 \mathrm{~kg}$. Median changes in total cholesterol, LDL cholesterol and triglycerides during the study were not clinically significant.

The efficacy and safety of aripiprazole combined with lamotrigine was evaluated in the long-term maintenance treatment of individuals with bipolar I disorder, recently manic or mixed. ${ }^{20}$ This two-phase study included a single-blind stabilization phase wherein subjects were stabilized with aripiprazole $10-30 \mathrm{mg} /$ day + lamotrigine $100-200 \mathrm{mg} /$ day. The stabilization period was up to 8 weeks. Individuals who were stabilized were randomly assigned to continue with aripiprazole + lamotrigine $(n=178)$ or lamotrigine + placebo $(n=173)$. More patients in the aripiprazole group $(36.5 \%)$ than in the placebo (21.9\%) group completed the study largely due to higher placebo discontinuation rate $(31.2 \%)$ due to inefficacy. The mean dose of aripiprazole was $18.2 \mathrm{mg} /$ day. The mean dose of lamotrigine was $172 \mathrm{mg} /$ day. The primary efficacy end-point was time from randomization to relapse into a manic or mixed episode operationalized as hospitalization, symptomatic worsening of illness and/or discontinuation due to inefficacy. The aripiprazole combination treatment arm showed a lower relapse rate when compared to lamotrigine monotherapy, but the result did not reach statistical significance. A similar finding was demonstrated for time to relapse to any affective episode. In the mixed episode subpopulation, subjects receiving aripiprazole and lamotrigine had a significant delay in the time to depressive relapse compared with placebo + lamotrigine $(\mathrm{p}=0.041)$. During the relapse assessment phase, there were no TEAEs in aripiprazole treated patients occurring in $>5 \%$ of subjects and at twice the rate of placebo. The overall mean weight change at the end of the double-blind phase was $0.43 \mathrm{~kg}$ in the combination group versus $-1.81 \mathrm{~kg}$ in the lamotrigine monotherapy group $\mathrm{p}=0.01$.

Recently, aripiprazole was compared to placebo as an adjunct to lithium or valproate for the maintenance treatment i.e. 52 weeks in bipolar I disorder. ${ }^{21}$ Adjunctive aripiprazole treatment significantly delayed time to any relapse when compared with adjunctive placebo (hazard ratio $=0.54$ ). Moreover the relapse rate for aripiprazole after 52 weeks was $17 \%$ and $29 \%$ with placebo. The most common TEAEs were headache, weight increase, tremor, and insomnia. 


\section{Summary}

Aripiprazole is established as efficacious in the maintenance treatment of BD on the basis of monotherapy and adjunctive data. A consistent finding with aripiprazole is minimal change in body composition and metabolic parameters. Moreover, prolactin elevation is not encountered, nor is there any evidence of mood destabilization. Aripiprazole is associated with EPS (notably akathisia) which is usually mild and not treatment limiting. Aripiprazole has not been established as efficacious in the acute or maintenance treatment of bipolar depression. ${ }^{22}$ Moreover, aripiprazole has two negative studies in acute bipolar depression. ${ }^{20}$ $\mathrm{BD}$ is usually treated with polypharmacy; combination studies with extended maintenance phases with lithium and possibly antidepressants would be interesting for future research.

\section{Disclosure}

RS McIntyre is on the Advisory Board for Astra Zeneca, Bristol-Myers Squibb, France Foundation, GlaxoSmithKline, Janssen-Orth, Solvay/Wyeth, Eli Lilly, Organon, Lundbeck, Bioavail, Pfizer, Shire and Schering-Plough; is on the Speaker's Bureau for Janssen-Ortho, Astra-Zeneca, Eli Lilly, Lundbeck, Bioavail and Wyeth; has Continuing Medical Education activities with Astra-Zeneca, Bristol-Myers Squibb, France Foundation, I3CME, Solvay/Wyeth, Physicians' Postgraduate Press, CME Outfitters, Optum Health, Schering-Plough and Eli Lilly; receives research grants from Eli Lilly, Janssen-Ortho, Shire and Astra-Zeneca; and receives travel funds from Bristol-Myers Squibb.

\section{References}

1. McIntyre RS, Soczynska JK, Woldeyohannes HO, Miranda A, Konarski JZ. Aripiprazole: pharmacology and evidence in bipolar disorder. Expert Opin Pharmacother. 2007;8(7):1001-1009.

2. Kinghorn WA, McEvoy JP. Aripiprazole: pharmacology, efficacy, safety and tolerability. Expert Rev Neurother. 2005;5(3):297-307.

3. Bristol-Myers Squibb Company, Otsuka America Pharmaceutical Inc. Aripirazole Product Monograph. Product Monograph. 10-1-2006.

4. DeLeon A, Patel NC, Crismon ML. Aripiprazole: a comprehensive review of its pharmacology, clinical efficacy, and tolerability. Clin Ther. 2004;26(5):649-666.

5. Stahl SM. Dopamine system stabilizers, aripiprazole, and the next generation of antipsychotics, part 2: illustrating their mechanism of action. J Clin Psychiatry. 2001;62(12):923-924.

6. Bowles TM, Levin GM. Aripiprazole: a new atypical antipsychotic drug. Ann Pharmacother. 2003;37(5):687-694.

Neuropsychiatric Disease and Treatment

\section{Publish your work in this journal}

Neuropsychiatric Disease and Treatment is an international, peerreviewed journal of clinical therapeutics and pharmacology focusing on concise rapid reporting of clinical or pre-clinical studies on a range of neuropsychiatric and neurological disorders. This journal is indexed on PubMed Central, the 'PsycINFO' database and CAS, and is the official
7. Wood MD, Scott C, Clarke K, et al. Aripiprazole and its human metabolite are partial agonists at the human dopamine D2 receptor, but the rodent metabolite displays antagonist properties. Eur J Pharmacol. 2006;546(1-3):88-94.

8. Aihara K, Shimada J, Miwa T, et al. The novel antipsychotic aripiprazole is a partial agonist at short and long isoforms of D2 receptors linked to the regulation of adenylyl cyclase activity and prolactin release. Brain Res. 2004;1003(1-2):9-17.

9. Tadori Y, Miwa T, Tottori K, et al. Aripiprazole's low intrinsic activities at human dopamine D2L and D2S receptors render it a unique antipsychotic. Eur J Pharmacol. 2005;515(1-3):10-19.

10. Keck PE Jr, Calabrese JR, McQuade RD, et al. A randomized, doubleblind, placebo-controlled 26-week trial of aripiprazole in recently manic patients with bipolar I disorder. J Clin Psychiatry. 2006;67(4):626-637.

11. Chessick CA, Allen MH, Thase M, et al. Azapirones for generalized anxiety disorder. Cochrane Database Syst Rev. 2006;3:CD006115.

12. McIntyre RS, Konarski JZ. Tolerability profiles of atypical antipsychotics in the treatment of bipolar disorder. J Clin Psychiatry. 2005;66 Suppl 3:28-36.

13. Keck PE, et al. 26-Week Aripiprazole vs Placebo Maintenance. J Clin Psychiatry. 2004;67(4):626-637.

14. Bowden CL, Calabrese JR, Sachs G, et al. A placebo-controlled 18-month trial of lamotrigine and lithium maintenance treatment in recently manic or hypomanic patients with bipolar I disorder. Arch Gen Psychiatry. 2003;60(4):392-400.

15. Tohen M, Calabrese JR, Sachs GS, et al. Randomized, placebo-controlled trial of olanzapine as maintenance therapy in patients with bipolar I disorder responding to acute treatment with olanzapine. $\mathrm{Am} \mathrm{J}$ Psychiatry. 2006;163(2):247-256.

16. Keck PE, Calabrese JR, McIntyre RS, et al. Aripiprazole monotherapy for maintenance therapy in bipolar I disorder: a 100-week, double-blind study versus placebo. J Clin Psychiatry. 2007;68(10):1480-1491.

17. Keck PE, Orsulak PJ, Cutler AJ, et al. Aripiprazole monotherapy in the treatment of acute bipolar I mania: a randomized, double-blind, placeboand lithium-controlled study. J Affect Disord. 2009;112(1-3):36-49.

18. Vieta E, Owen R, Baudelet C, McQuade RD, Sanchez R, Marcus RN. Assessment of safety, tolerability and effectiveness of adjunctive aripiprazole to lithium/valproate in bipolar mania: a 46-week, open-label extension following a 6-week double-blind study. Curr Med Res Opin. 2010;26(6):1485-1496.

19. Vieta E, T'joen C, McQuade RD, et al. Efficacy of adjunctive aripiprazole to either valproate or lithium in bipolar mania patients partially nonresponsive to valproate/lithium monotherapy: a placebo-controlled study. Am J Psychiatry. 2008;165(10):1316-1325.

20. Carlson BX, Sun W, Timko K, et al. Efficacy and safety of aripiprazole in combination with lamotrigine in a long-term maintenance study in manic or mixed subjects with bipolar I disorder (CN138-392). Proceedings of the 50th annual meeting of the New Clinical Drug Evaluation Unit (NCDEU); 2010 Jun 14-17; Boca Raton, Florida.

21. Marcus R, Khan A, Rollin L et al. Efficacy of aripiprazole adjunctive to lithium or valproate in the long-term treatment of patients with bipolar I disorder with an inadequate response to lithium or valproate monotherapy: a multicenter, double-blind, randomized study. Bipolar Disord. 2011;13(2):133-144.

22. Thase ME, Jonas A, Khan A, et al. Aripiprazole monotherapy in nonpsychotic bipolar I depression: results of 2 randomized, placebo-controlled studies. J Clin Psychopharmacol. 2008;28(1):13-20.

\section{Dovepress}

journal of The International Neuropsychiatric Association (INA). The manuscript management system is completely online and includes a very quick and fair peer-review system, which is all easy to use. Visit http://www.dovepress.com/testimonials.php to read real quotes from published authors. 